\title{
Chapter 11 \\ Textile as Material in Human Built Environment Interaction
}

\author{
Preben Hansen, Vesna Grujoska, and Milica Jovanoska
}

\begin{abstract}
As human population grows in number, the amount of (organic and nonorganic) waste materials has grown rapidly year by year.

Changes of consumption and lifestyle have generated a higher waste amount. Waste management has become a significant issue in today's society. In 2014, the EU countries registered 2.494 million tons of generated waste, which was an increase in growth of $2.8 \%$ compared with data from 2008. Different renewable materials are ending up as waste, such as glass, paper, plastic, textile, which may be used in a recycling process. This chapter will discuss these challenges with the focus on one of these materials, textiles, as building materials.

We also introduce the perspective of Human-Computer Interaction (HCI) aspects, and especially Human-Built Environment Interaction which will give some specific focus on textiles used as recycled materials. The result of the critical literature review in the area of textiles as building material from an HCI point of view suggest a set of interaction design dimensions that can be considered and applied on the usage of textiles for built environments.
\end{abstract}

Keywords Smart textile materials · Insulation · Human-building interaction · Regenerative $\cdot$ Recycled materials

\footnotetext{
P. Hansen $(\bowtie)$

Department of Computer and Systems Sciences/DSV, Stockholm University, Kista, Sweden

e-mail: preben@dsv.su.se

V. Grujoska $\cdot$ M. Jovanoska

Ss. Cyril and Methodius University, Skopje, North Macedonia

e-mail: vesna.grujoska@gf.ukim.edu.mk; m.jovanoska@gf.ukim.edu.mk
} 


\subsection{Introduction}

Societal and human concerns about environmental impacts of building practices and materials have been expressed through a growing demand, production, and use of "green" building products (Corscadden, Biggs \& Stiles, 2014). At the same time, there is a strong movement in Europe to explore how to integrate natural resources with bioproducts and renewable resources into different industries. For example, bio-design products are one emerging area (Wang, Luo, Liu, Lu, \& Hansen, 2017) that may guide humans in changing behaviors for a more engaging lifestyle. Moreover, the building and construction sector is concerned with different materials in order to materialize an engineering idea or model. When it comes to the ecological impact of the production processes of recycled textiles, some countries have a greater demand of different types of textiles compared to others. Part of this demand is based on new implemented top-down regulations, laws, and policies, another part is due to some changes in the business environmental codes (H\&M, 2019) and yet another part emerged from bottom-up through people changing their behavior (Parviainen, Lagerström, \& Hansen, 2017). Different types of textile materials are, on an everyday basis, discarded and are increasingly considered when it comes to how to recycle, reuse, and use textiles for extensions, additions, and substitutions in different contexts.

The public acceptance and market penetration of the environmentally certified buildings, such as BRE Environmental Assessment Method (BREEAM) and Leadership in Energy and Environmental Design (LEED) is growing, for example, in Stockholm, Sweden. This can be shown through the growth of the environmental awareness of the consumers that are willing to pay more for a green certificate. This process is followed by lots of international, national, regional, and local initiatives and future strategies. Sustainable development is the overall goal of the Organization for Economic Co-operation and Development (OECD) that developed the Green Growth Strategy (OECD Green growth and sustainable development, 2019). The City of Stockholm adopted its first environmental program in 1976 (The Stockholm Environment Program, 2016). Since then, a line of programs has been developed. The environmental program for 2016-2019 is the ninth environmental program and one of the reasons why Stockholm is one of the leading green capitals in Europe regarding sustainability moving in this direction in both governmental, public, and business environments.

For the development of sustainability, Swedish authorities have developed and also adopted the Environmental Code (The Swedish Environmental Code, 2000). This code represents modernized, broadened, and more stringent environmental legislation. The main objectives that this Environmental Code is regulating are: human health; natural and cultural environments; biodiversity; use of land, water, and the physical environment; and the reuse and recycling, as well as other management of materials, raw materials, and energy, of which the last part is of interest to this chapter. 
The aim of this chapter is to introduce some fundamentals from the areas of build environments, especially considering textiles as building material, and, on the other hand, general aspects from the Human-Computer Interaction (HCI) discussing the potential of a new emerging research field of Human-Built Environment Interaction, with the focus especially on using textiles as building material.

The chapter first gives a brief overview of production, recycling, and reuse of textiles, followed by a section concentrating on the issues how textiles could be used as building material. Examples of wool and cotton are given. The final section then introduces an emerging research field within HCI, dealing with how people interact with built environments.

\subsection{Methodology}

From a methodological perspective, this chapter is based on a critical literature review. This involves selecting and filtering a set of papers and articles in order to perform a literature in the field(s), but choosing a representative set, and thus, it will not cover entire fields of practices or research. The area scoped out provides first with a literature overview on textiles as material and some of its relevant conditions, especially when considered within the built environment. Finally, the Human Built Environment Interaction is presented. This is followed by introducing its possible application in HCI as an emerging research area, especially focusing on the interaction with built environments. The subarea of human-interaction with textiles and built environments is considered, as an emerging and challenging area.

\subsection{Textiles: Production, Recycling, and Reuse}

In our society, textiles are fundamental, not only providing us with clothing and footwear, but also as components in our homes through carpets, curtains, and furniture. Furthermore, textiles are used in our workplaces, in public transportation, in public urban places, and buildings. The downside is that the textile production, usage, and consumption have a large environmental and climatic impact by using natural resources and chemicals.

According to European Environment Agency (EEA), Europeans are consuming on average $26 \mathrm{~kg}$ of textiles per person per year (EEA, 2019). In this report, it is highlighted that EU citizens and consumers discard around $11 \mathrm{~kg}$ of textiles per person and per year. The amount of discarded textiles, textile waste, is mostly exported as used clothes, mainly to eastern European countries, Asia, and Africa. This is an increasing activity. Used clothes not exported are mostly incinerated or landfilled. This means that the recycling rate of textiles is low. At least $50 \%$ of the material that ends on landfills could be reused (Briga-Sa et al., 2013). Textile recycling may offer the following environmental benefits: 
- Decrease landfill space requirements

- Avoid use of virgin fibers

- Reduce consumption of energy and water

- Avoid pollution

- Lesser demand for dyes.

However, despite the benefits mentioned above, the production process of textile is causing a lot of damage and fatigue to the environment as well as to the humans, especially the people working in the production process and, as such, the textile industry is a significant pollution factor for water, soil, and air (Table 11.1).

More specifically, in the production of textiles, synthetic dyes are used for fabrics which have high levels of sulfur, nitrates, acetic acid, soaps, enzymes, chromium compounds, and heavy metals, such as copper, arsenic, lead, cadmium, mercury, nickel, and cobalt. Furthermore, reaction of dyes with chlorine can induce carcinogenic products.

The reuse and recycling of used clothing reduces the environmental burden compared with the purchase of clothing obtained from the original fiber. One way of dealing with this issue is to consider the concept of recycling, reusing, and reducing (RRR). All three levels of recycling, reusing, and reducing can be used as a way of considering the material usage in new ways. We will look closer at cotton and wool as examples, but other natural and organic fabrics are hemp, angora, silk, linen, and bamboo.

Cotton is a natural material that requires big amounts of water for the cultivation process. Even the decomposition process of the cotton fiber is followed up with production of methane. Synthetic fibers biodegrade slower than the natural ones. An important part of cotton produced worldwide is part of the textile fibers used for the production of Denim garments. Types of pollution for cotton is air pollution, water contamination, and solid fabric waste (Zhou, Zheng, Li, \& Lu, 2010).

Another natural material that can be used in building is sheep wool. Fibrous agricultural materials, such as straw, flax, cotton, and hemp, have been investigated as potential insulating products, and they are examples of the transition towards more sustainable materials in the construction of homes and other built structures

Table 11.1 Environmental impacts generated by textiles

\begin{tabular}{l|l|l|l|l}
\hline Fabric and cloth production & \multicolumn{3}{l}{ Impact } \\
\hline Activity & Environmental aspects & Health & Water & Air \\
\hline Ironing & $\begin{array}{l}\text { Consumption of electricity and occupational } \\
\text { diseases }\end{array}$ & $\mathrm{x}$ & $\mathrm{x}$ & $\mathrm{x}$ \\
\hline Clothing sewing & $\begin{array}{l}\text { Consumption of human energy, and textiles and } \\
\text { metal waste }\end{array}$ & $\mathrm{x}$ & & \\
\hline Cloth cutting & Noise generation & $\mathrm{x}$ & & $\mathrm{x}$ \\
\hline Bleaching of tissue & Generation of liquid waste & & $\mathrm{x}$ & \\
\hline Cloth dyeing & Generation of liquid waste & & $\mathrm{x}$ & \\
\hline Cloth wash (Denim) & Water consumption & & $\mathrm{x}$ & \\
\hline
\end{tabular}

From Pichardo et al. (2017) 
(Corscadden et al., 2014). Next section presents an emerging research area, in which textiles can be considered as particular interesting elements when moving from focusing on its physical and chemical condition as a material towards a material that humans can interact with in new contexts and as new concepts.

Textiles and its characteristics and conditions that can be exploited and utilized linked to the human not only as clothing and coverings but also as functional, esthetic, emotional, and practical material in different aspects of interior and architectural design, both in urban as well as in rural environments.

\subsection{Textile as a Building Material}

As mentioned in the previous section, textile waste is extensive. The production processes of traditional materials for insulation (acoustic and thermal insulation) cause a negative impact on the environment. As a consequence, a new 'green' approach started to emerge. It proposes to introduce new eco-friendly alternatives that include low production costs, and focus on the reuse of waste material in combination with fibrous (porous) structures, which make the recycled textile an interesting solution for building sustainable panels for insulation treatments.

In the previous section, we mentioned fabrics and textiles as possible materials in built environments. According to Pichardo, Martínez-Barrera, Martínez-López, Ureña-Núñez, and Ávila-Córdoba (2017), the use of textile fibers can solve at least two problems, serving a dual function: (a) elimination of an environmental pollutant, and (b) creation of an alternative material for the construction industry. Sheep wool is a bioproduct that has demonstrated some potential and has begun to be marketed and promoted as an alternative insulating material. Wool has several physical attributes that make it attractive as insulation, including strength, hydrophobic and hydrophilic characteristics, thermal performance, and the ability to regulate temperatures and fire resistance (Ye, Wells, Carrington, \& Hewitt, 2006). Wool itself is a renewable resource and sheep wool has a low environmental impact, yet the use of alternative materials, particularly sheep's wool, can still be considered an emerging research topic.

A study by Ballagh (1996) based on the properties of wool concluded that wool isolates vibrations, reducing the sound index by up to six decibels. Desarnaulds et al. (2005) found that sheep's wool has better sound absorption than mineral wool. Johnson et al. (2003) identified another potential use for sheep wool as a technical fiber, due to wool's unique physical attributes. Thermal conductivity is typically used to characterize the insulation properties of a material (Corscadden et al., 2014).

The reuse of materials, and especially textiles, is an area of great interest and with potential application due to the high amount of waste it produces around the world. Their integration can be carried out as thermal or acoustic insulation, structural reinforcement, or as coating and finishing material, among others. Different materials and waste with different origins have been studied. Research has been developed to study the potential application of natural material as thermal insulation 
(Korjenic, Petranek, Zach, \& Jitka, 2011). Textile waste integrates the group of reusable materials that can be included in the building construction and could have different possibilities of application (Briga-Sa et al., 2013). The textile wastes can be from clothes that are no longer used or fabrics as part from other objects, like furniture, etc. Fibers could also be those recovered from various waste streams, which could be suitable for lightweight concrete reinforcement (Zhou et al., 2010). Textile cutting waste has also been mixed with epoxy resin and foundry sand for producing a composite material used for lightweight construction (Pichardo et al., 2017). Regarding thermal insulation, thermal conductivity of the materials $(\lambda)$ is the most important characteristic that should be considered since thermal conductivity is a measurement of the ability of a material to transmit heat. Measurements of this parameter have shown that the recycled textile considered have convenient properties as a thermal insulation material. Moreover, fibrous materials have good sound absorbing potential. The acoustic efficiency of the textile was confirmed by analyzing the thermal and acoustic insulation, like cellulose fibers mixed into concrete (Paiva et al., 2011; Briga-Sa et al., 2013; Pichardo et al., 2017).

A variety of techniques for textile recycling exist, but they can mainly be divided into mechanical and chemical techniques (Hawley, 2006). Recycled textile waste can be mechanically re-structured into yarns, woven fabrics, nonwoven fabrics, etc. In order to avoid the use of toxic binders, for producing recycled textiles from natural and synthetic fibers, needle-punching technique can be used. The structure of the textile (mostly polyethylene) is consolidated without any binder, by interlacing the fibers.

The development of smart textiles has grown and is guided by material sciences, especially the new findings at fiber level (e.g., Cherenack \& van Pieterson, 2012). However, not everything that is technologically possible is useful; nonetheless, smart textiles bring interactive and dynamic possibilities and introduce the human into the research, production, and use of smart textiles in different situations. Refs needed Smart materials are materials that possess the ability to modify their physical properties in a specific way as a response to a specific external trigger. This means that a smart material may contain sensors, actuators, and controlling mechanisms which make it able to detect the stimulus, respond to it in a specific manner and intensity, in an appropriate time, and return to the original state as soon as the stimulus is removed. Depending on the type of the trigger, smart materials can be:

- Piezoelectric materials (e.g., Chalioris et al., 2016)

- Thermo-responsive materials

- Magneto restrictive materials (e.g., Dapino, 2004)

- PH-sensitive materials

- Chromogenic systems (e.g., Lampert, 2004). 


\subsection{Human-Built Environment Interaction}

The process of recycling textiles do not only responds positively to environmental and economic aspects but also gives the opportunity to the user to be part of the procedure by choosing personal belongings for recycling or designs which gives personality to the final product. This is particularly pronounced when using textiles in acoustic treatment. As such, the user interaction with the final product with which he/she has a personal relationship will enhance the experience and understanding of the life cycle of natural materials and their conditions.

Today, the elements of the built environment, such as buildings in urban and rural contexts encompassing both private and public spaces, are quickly changing and are being reconceptualized in different ways, aiming at supporting our lives in the spaces where we live (Parviainen et al., 2017). New demands and awareness are beginning to arise on the fact that we, as humans who live in the built environments, need to be involved in reshaping our needs, behavior, and visions. We want to know not only how our food, air, and soil are being treated but also the built environments that surrounds us. By designing and equipping our built environment with new technologies, such as Internet of Things (IoT) and sensors, we create new ways of interacting with our built environment.

This means that we, as humans, are moving between different and more complex spaces, so called 'blended spaces' (Benyon, 2012). A blended space involves both our physical world, as well as digital habitat spaces, and we can interact with and between them. In the state of a blended space, we may redefine our habits, needs, demands, and our knowledge and awareness about why and how we want to live our lives. One such redefinition is about the materials that surround us in different forms. Usually, specific materials have their functions, purpose, and task to fulfill, both socially and culturally. However, our conceptualization is that a material has a certain function and we get used to that. It is rarely that we discuss about how a specific material that we use for a specific function/purpose actually can be reshaped or evolve into another purpose and function.

Within the research field of HCI, a specific research area has emerged, called Human-Building Interaction (Alavi et al., 2019a). From within HCI (including Industrial and Interaction Design), the focus is on how humans (or agents) and artefact interact within the spaces they are located in. One of the aspects raised within architectural practices includes ecological and sustainable concerns and the use and utility of materials (such as textiles). According to Alavi et al. (2019b), HumanBuilding Interaction can be studied encompassing the complexity of people's experiences in built environment that also integrates computing in different forms. Important interconnected phenomena of the building to study can be: the physicalmaterial, the spatial-configurational, and the social-cultural aspects (Alavi et al., 2019b). In addition, a blended space (Benyon, 2012) aspect can be included, involving people moving between digital and physical spaces. Built environments with different functions (homes, workplaces, hospitals, parks, public transportation, 
educational buildings, etc.) bring up a range of contextual requirements that entail the development of focused research.

An interesting approach suggested by Sijakovic and Peric (2018) is discussing the possibility of implementing the biological concept of symbiosis into the field of architecture for redefining the design principles of architectural recycling of resources. The concept of symbiosis serves for the definition of a possible relationship between existing buildings and new intervention in the process of architectural recycling. According to Sijakovic and Peric (2018), the translation and transformation of the biological principles is possible due to a set of criteria for the redefinition of design principles: structure, material, form, and spatial organization. Related to the topic of this chapter is the first of the three redefined design principles: the criteria for building tectonics, which focuses on the interaction between structural elements and material. The tectonic criteria dealing with structure are understood as either that (a) old and new materials are interwoven or (b) a clear division can be seen between the old and new material (Sijakovic \& Peric, 2018). One of the purposes of using a symbiotic approach is to allow at least one part of the relationship to benefit either the structure, material, formal, or spatial enhancements.

Textile materials have several properties, such as sensing, flexibility, durability, weight, water absorbance, strength, insulation, etc. Textiles in different forms constitute a medium that bridges the interaction between humans and the humans' world, such as buildings. Even though adding computation like sensors and other technologies to the textile, the interactive textile is enabled with sensing or actuating properties. From an HCI and Interaction Design point of view, there might be several interaction design dimensions (Hallnäs, 2011) involved in the design space for which textiles and textile waste can be framed: Timing, Spacing, Connectivity, and Methodology. Timing refers to how both non-interactive and interactive textile change over time in different ways, such as fading, structure decomposing, and strength. Spacing refers to the fact that all textiles introduce a space. The material itself is a space and as such could embed other properties. Connectivity refers to the interface. The interface could be physical or non-physical. The textile material enables interaction and connectivity. For example, if one would know that the clothes of a certain person or his/her family were used for insulation, he/she would have a very special connection to his/her apartment, house, and even to a particular wall. One's behavior may change due to this knowledge. Methodology refers to the ways in which one uses the material (Persson, 2013, 108-109). This includes the different ways a person may interact with textiles. We all have our relationship, experiences, and memories of a specific material. One of the goals of research within this area is to explore and find new approaches on how we see textiles from a time-perspective, how textiles can enhance, change, populate our spaces and how new types of interaction patterns and behavior could emerge. This will then also lead to the development of new methodologies on how we approach and use textiles in our daily lives, as well as in professional work situations, as part of our built environments. Another interesting example is the breathing wall. It is a system 
using textiles that merges normal insulation systems and characteristics of thermal exchange of building walls (Youssef, 2017) and thus interact with humans. Therefore, when the sensor is sensing any changes in the temperature, metal strings bend, decreasing the space between the textile strings, which causes a reshaping of the textile.

By introducing the electronics within smart textiles, the environmental sustainability is decreased because of the difficulties in the recycling process of the electronics, but the concept of the smart materials enhances societal sustainability regarding the personalization and interaction that increase the value of the smart textiles in built environments.

\subsection{Concluding Remarks}

Textile waste is a problem for the environment and may become a worse problem without recycling or other means to lower its environmental impacts. The discussion presented in this chapter on different types of textiles has shown that, after recycling, this type of material has convenient properties to be reused as a building material.

Recycled textile can be used in different forms as structural and non-structural building material. Non-structural use of the recycled textile as a thermal and acoustic insulation was considered in this work. The results have shown that textiles are promising materials and have still open field of work for more advanced development.

The application of a smart concept, through the use of electronics, gives textiles another value. Although the environmental sustainability is lower in that case due to the use of electronics, the interaction possibilities opens up new potential in the societal sustainability. Research in this field is currently intense, the potential and flexibility of these smart materials is perceived and only engineers' and designers' creativity can set or break the limits of their application.

This chapter has provided with a reflective analysis on considering textiles as material in built environments from a regenerative point of view. We hope that research, both from the built environment and HCI communities, can benefit from each other when developing material, material usage, and recycling, as well as involving and embedding human interaction with these materials for the development of more sustainable built environments. We have pointed out several conditions for how to relate HCI with textile as material, especially connected to the built environment as an emerging research field. We show that the importance of exploring textiles as material for interaction design is vital and important from a design and from a circular economy perspective by looking at the spatial and temporal design aspects of textiles, elements that will enable interaction. 


\section{References}

Alavi, H., Churchill, E., Wiberg, M., Lalanne, D., Dalsgaard, P. Fatah Gen Schieck, A. \& Rogers, Y. (2019a). Introduction to Human-Building Interaction (HBI): Interfacing HCI with Architecture and Urban Design. ACM Transaction in Computer-Human Interaction, 26(2), Article 6 (March 2019), 10 pages. https://doi.org/10.1145/3309714

Alavi, H., Churchill, E., Wiberg, M., Lalanne, D., Dalsgaard, P., Schieck, A., et al. (2019b). HumanBuilding Interaction: Sketches and grounds for a research program. Interactions, 26(4), 58-61. https://doi.org/10.1145/3330342

Ballagh, K. O. (1996). Acoustical properties of wool. Applied Acoustics, 48, 101-120. https://doi. org/10.1016/0003-682X(95)00042-48

Benyon, D. (2012). Designing Blended Spaces. In BCS-HCI '12 Proceedings of the 26th Annual BCS Interaction Specialist Group Conference on People and Computers. dl.acm.org. BCS-HCI. pp. 398-403.

Briga-Sa, A., Nascimento, D., Teixeira, N., Pinto, J., Caldeira, F., Varum, H., et al. (2013). Textile waste as an alternative thermal insulation building material solution. Construction and Building Materials, 38, 155-160.

Chalioris, C., Karayannis, C., Angeli, G., Papadopolous, N., Favata, M., \& Providakis, C. (2016). Applications of smart piezoelectric materials in a wireless admittance monitoring system (WiAMS) to Structures - Tests in RC elements. Case Studies in Construction Materials, 5(December 2016), 1-18.

Cherenack, K., \& van Pieterson, L. (2012). Smart textiles: Challenges and opportunities. Journal of Applied Physics, 112, 091301. https://doi.org/10.1063/1.4742728

Corscadden, K. W., Biggs, J. N., \& Stiles, D. K. (2014). Sheep's wool insulation: A sustainable alternative use for a renewable resource? Resources, Conservation and Recycling, 85, 9-15.

Dapino, M. (2004). On magnetostrictive materials and their use in adaptive structures. Structural Engineering and Mechanics, 17(3-4), 1-27.

Desarnaulds, V., Costanzo, E., Carvalho, A., \& Arlund, B. (2005). Sustainability of acoustic materials and acoustic characterization of sustainable materials. In: Proceedings of ICSV12

EEA. (2019). Textiles in Europe's circular economy. Briefing no 10/2019. PDF TH-AM-19-011EN-N - ISBN 978-92-9480-106-7 - ISSN 2467-3196. https://doi.org/10.2800/904911

Government of Swedish Offices. (2000) The Swedish environmental code. Ministry of the Environment. Ds 2000:61 https://www.government.se/legal-documents/2000/08/ds-200061/. Accessed 24 Jan 2019

H\&M. (2019). H\&M sustainability report 2018. Stockholm: H\&M. https://sustainability.

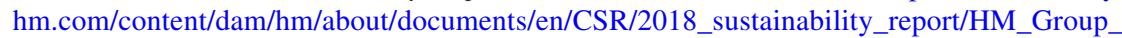
SustainabilityReport_2018_\%20FullReport_en.pdf. Accessed 24 Jan 242019.

Hallnäs, L. (2011). On the foundations of interaction design aesthetics: Revisiting the notions of form and expression. International Journal of Design, 5(1), 73-84.

Hawley, J. (2006). Textile recycling: A system perspective. Recycling in textiles (pp. 7-24). Woodhead Publishing Series in Textiles https://doi.org/10.1533/9781845691424.1.7

Johnson, N., Wood, E., Ingham, P., McNeil, S., \& McFarlane, I. (2003). Wool as a technical fibre. Journal of Text Inst, 94, 26-41. https://doi.org/10.1080/00405000308630626

Korjenic A., Petranek, V., Zach, J. \&, Jitka, H. (2011). Development and performance evaluation of natural thermal-insulation materials composed of renewable resources. Energy and Buildings, $43,2518-2523$.

Lampert, C. (2004). Chromogenic smart materials. Materialstoday, 7(3), 28-35.

OECD. Green growth and sustainable development. Paris: OECD. https://www.oecd.org/greengrowth/. Accessed 24 Jan 24, 2019.

Paiva, A., Varum, H., Caldeira, F., Sá, A., Nascimento, D. \& Teixeira, N. (2011). Textile subwaste as a thermal insulation building material. In 2011 International conference on petroleum and sustainable development. IPCBEE vol. 26 (2011) @ (2011). Singapore: IACSIT Press. 
Parviainen, E., Lagerström, E. \& Hansen, P. (2017). Composting as interior design - Encouraging sustainability throughout a participatory design process. In DIS '17 companion proceedings of the 2017 ACM Conference Companion Publication on Designing Interactive Systems. June, 2017, Edinburgh, UK. pp. 167-171. https://doi.org/10.1145/3064857.3079139

Persson, A. (2013). Exploring textiles as materials for interaction design. Studies in artistic research No 4, 2013. Doctoral thesis, University of Borås. ISBN: 978-91-85659-88-3

Pichardo, P., Martínez-Barrera, G., Martínez-López, M., Ureña-Núñez, F., Ávila-Córdoba, L. (2017). Waste and recycled textiles as reinforcements of building materials, In Guay, E. (Ed.), Natural and artificial fiber-reinforced composites as renewable sources. IntechOpen. https://doi.org/10.5772/intechopen.70620.

Sijakovic, M., \& Peric, A. (2018). Symbiotic architecture: Redefinition of recycling design principles. Frontiers of Architectural Research, 7, 67-79.

The Stockholm Environment Programme 2016-2019. (2016). Stockholm: City of Stockholm, Executive Office. https://international.stockholm.se/globalassets/rapporter/the-stockholmenvironment-programme-2016-2019.pdf. Accessed 24 Jan 2019.

Wang, Y., Luo, S., Liu, S., Lu, Y., \& Hansen, P. (2017). Crafting concrete as a material for enhancing meaningful interaction. In International Conference on Human-Computer Interaction (HCII) (pp. 634-644). Springer.

Ye, Z., Wells, C. M., Carrington, C. G., \& Hewitt, N. J. (2006). Thermal conductivity of wool and wool-hemp insulation. International Journal of Energy Resources, 30, 37-49. https://doi. org/10.1002/er.1123

Youssef, M. (2017). Kinetic behavior, the dynamic potential through architecture and design. International Journal of Computational Methods and Experimental Measures, 5(4), 607-618.

Zhou, X.-Y., Zheng, F., Li, H.-G., \& Lu, C.-L. (2010). An environment friendly thermal insulation material from cotton stalk fibers. Energy and Buildings, 42, 1070-1074. https://doi. org/10.1016/j.enbuild.2010.01.020

Open Access This chapter is licensed under the terms of the Creative Commons Attribution 4.0 International License (http://creativecommons.org/licenses/by/4.0/), which permits use, sharing, adaptation, distribution and reproduction in any medium or format, as long as you give appropriate credit to the original author(s) and the source, provide a link to the Creative Commons license and indicate if changes were made.

The images or other third party material in this chapter are included in the chapter's Creative Commons license, unless indicated otherwise in a credit line to the material. If material is not included in the chapter's Creative Commons license and your intended use is not permitted by statutory regulation or exceeds the permitted use, you will need to obtain permission directly from the copyright holder.

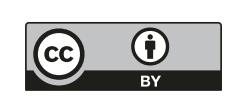

